\title{
CONFERÊNCIA
}

\section{HISTÓRIA E ENSINO DE MATEMÁTICA}

João Cláudio Brandemberg²

\section{INTRODUÇÃO}

O conhecimento acerca da origem e do desenvolvimento de conceitos matemáticos, como limites, grupos e funções, acreditamos, facilita, de forma significativa o desenvolvimento de um efetivo processo de ensino-aprendizagem da Matemática.

Para tanto, buscamos na História as explicações e o desenvolvimento conceitual desses conceitos (objetos, conteúdos) visando obter elementos que minimizem possíveis obstáculos de aprendizagem, que encontramos no ensino. Consideramos o desenvolvimento de um processo de ensinoaprendizagem, partindo de uma abordagem que caracterize tal desenvolvimento histórico dos conceitos estudados.

Tal abordagem deve propiciar ao graduando em Matemática uma possível contextualização histórico-epistemológica dos conteúdos, constituindo-se em um elemento significante no processo. Assim, com a utilização dos aspectos históricos no ensino, buscamos não só motivar o aluno, mas proporcionar uma apresentação dos conteúdos que garanta o processo de (re) construção do conhecimento.

Afirmamos que este conhecimento, obtido a partir da história, nos possibilita, além de segurança nas discussões, realizar boas escolhas dos conteúdos a serem ensinados, bem como de estratégias metodológicas e dos recursos didáticos nos cursos de graduação em matemática.

\footnotetext{
1 Texto produzido a partir de uma conferência realizada em setembro de 2015 na Universidade Federal do Oeste do Pará - UFOPA.

2 Doutorado em Educação pela Universidade Federal do Rio Grande do Norte. Professor Associado II da faculdade de matemática - FACMAT-ICEN/UFPA e do PPGECM-IEMCI/UFPA. E-mail: brand@ufpa.br.
} 


\section{SOBRE A DISCIPLINA HISTÓRIA DA MATEMÁTICA EM CURSOS DE GRADUAÇÃO}

Do ponto de vista das discussões que perpassam o ensino de história da matemática na graduação em universidades brasileiras, podemos discutir aspectos de sua implantação como disciplina e de sua importância para o processo de ensino-aprendizagem de Matemática.

Para começar, citamos alguns (três) trabalhos que trazem essa conotação em suas formulações e desenvolvimento teórico.

Um trabalho desenvolvido pelo professor Miguel Chaquiam, 2005-2006, intitulado "Trilhos da Matemática: um resultado da disciplina História da Matemática" nos apresenta aspectos da importância da discussão da vida e obra de matemáticos famosos no processo. Nessa linha, nos aparecem os textos "Uma proposta para a disciplina História da Matemática" de Jamur Venturin (2011) e "História da Matemática: história de uma disciplina" de Maria Cristina Oliveira e Wagner Fragoso (2011).

Temos aqui uma preocupação com o formato que a disciplina apresenta depois de sua implantação, sua origem e discussão de conteúdos ou forma de apresentação dos conteúdos.

Em seu texto "O Uso da História no Ensino de Matemática: reflexões teóricas e experiências", publicado originalmente em 2001, o professor Iran Abreu Mendes apresenta esta discussão e ainda argumenta sobre o seu uso para o processo de ensino de conteúdos matemáticos, a partir do seu desenvolvimento histórico-epistemológico. Nesta linha, Fossa (2001) aponta para a apresentação de tópicos selecionados e Brandemberg (2010) amplia para o estudo de textos clássicos produzidos ao longo da História.

\section{A DISCIPLINA HISTÓRIA DA MATEMÁTICA NOS CURSOS DE GRADUAÇÃO NA UFPA}

A disciplina não consta nas resoluções de 1988 dos cursos de matemática, quando o reitor da Universidade Federal do Pará era o professor Seixas Lourenço. Na década de 1990 a disciplina é implantada no 
bacharelado e como optativa na licenciatura ${ }^{3}$. São dois, os nomes dados à época, a saber: Evolução da Matemática e Tópicos em História da Matemática.

A disciplina é implantada nos moldes da ministrada na Universidade de São Paulo - USP, a partir das necessidades argumentadas pelo professor Carlos Alberto Knudsen 4 , um grande incentivador do ensino da História da Matemática na UFPA.

A relação com o modelo aplicado na Universidade de São Paulo é tamanha que o conteúdo programático discutido é praticamente o mesmo realizado na USP, à época, incluindo as referências principais. O texto do programa apresenta na integra os 27 capítulos do livro de Carl B. Boyer, edição de 1993, sendo os quatro últimos, concentrados em uma unidade denominada "24 Aspectos do século XX".

Nesta abordagem a história da matemática se apresenta em uma sequência, puramente linear, que é caracterizada por sua divisão em períodos históricos, a saber: idade antiga (egípcios, babilônios e gregos), idade média (renascimento), idade moderna (matemática e simbolismo algébrico) e idade contemporânea (revolução científica).

Um formato que perdurou por cerca de duas décadas, como podemos ver na figura 01, apresentada a seguir, e que caracteriza o que denominamos de abordagem cronológica da história da matemática.

\footnotetext{
3 Tanto que em meu histórico de 1992 (licenciatura): não consta como disciplina obrigatória. 4 Professor da faculdade de matemática - FACMAT, durante por mais de 25 anos. Atualmente aposentado, mora em São Paulo.
} 
Figura 01: A apresentação do conteúdo desde a década de 1990 até 2009.

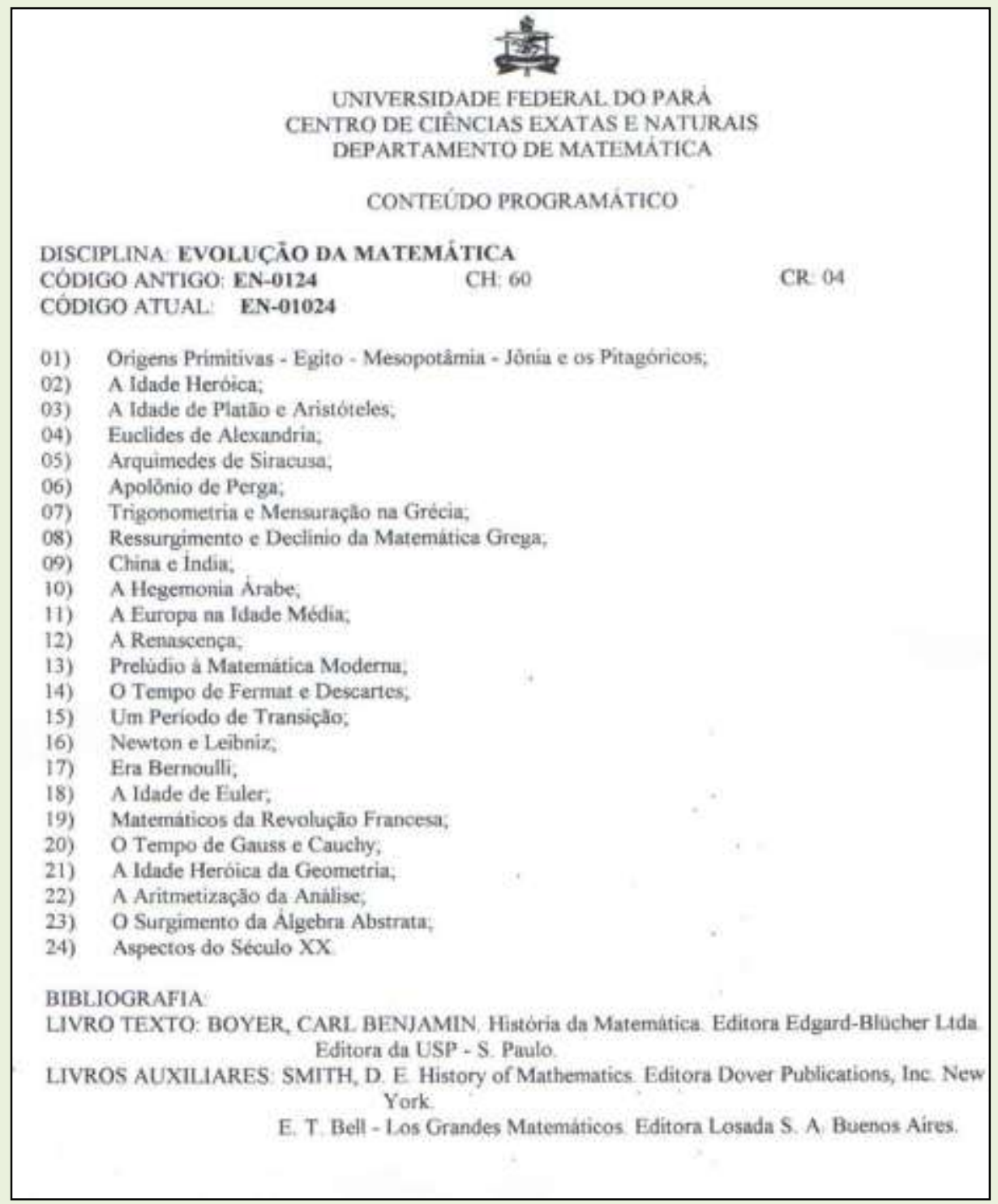

Fonte: Arquivos da FACMAT- ICEN/UFPA.

Como vimos destacando, buscamos a partir desta apresentação e das discussões originárias de nossa formação, buscamos tratar do uso da história da matemática como componente metodológico para o ensino de conteúdos (conceitos, objetos, ferramentas) matemáticos, mesmo que a partir de uma abordagem cronológica clássica, como a do quadro a seguir. 


\section{Abordagem Cronológica}

\section{HISTÓRIA DA MATEMÁTICA}

Carga horária: $60 \mathrm{~h}$

Ementa: A Matemática no antigo Egito. A Matemática na Mesopotâmia. A Matemática na China. A Matemática na Grécia Antiga. A Matemática no Islã. A Matemática do Renascimento. As Geometrias Não-euclidianas. Uma breve história da Álgebra. Uma breve história do Cálculo. Filosofia da Matemática.

Objetivos: estudar o desenvolvimento histórico dos conteúdos e do pensamento matemático desde a antiguidade até os dias de hoje, caracterizando as fontes, os autores e buscando a relevância dos problemas e suas soluções em cada período e as conexões com os problemas atuais.

Conteúdo programático:

01 - A Matemática no antigo Egito (06 horas).

Frações unitárias, falsa posição na determinação de uma quantidade desconhecida e problemas geométricos de área e volume.

02 - A Matemática na Mesopotâmia (06 horas).

O sistema de numeração sexagesimal, a resolução de equações do primeiro e segundo graus, problemas geométricos e ternos pitagóricos.

03 - A Matemática na China (05 horas).

Sistema de numeração, os nove capítulos sobre a arte da Matemática, a ocidentalização da matemática chinesa e as recreações.

04 - A Matemática na Grécia Antiga (07 horas).

Os inícios da Geometria, a aritmética pitagórica, a teoria dos incomensuráveis, os elementos de Euclides, trisseção, quadratura e duplicação, o Almagesto de Ptolomeu e a Aritmética de Diofanto. 05 - A Matemática no Islã (06 horas).

A Aritmética e a Álgebra de Al-Khwarizmi, a resolução de equações cúbicas e a trigonometria. 06 - A Matemática do Renascimento (séculos XII a XVI) (06 horas).

As contribuições de Leonardo de Pisa, Luca Pacioli, Tartaglia, Cardano, Bombelli, Ferrari e as equações de terceiro e quarto graus. O Ars Magna de Cardano.

07 - As Geometrias Não-euclidianas (05 horas).

As tentativas de Wallis, Saccheri e Lambert, a Geometria hiperbólica com Gauss, Bolyai e Lobatschewski e as geometrias elípticas de Riemann.

08 - Uma breve história da Álgebra (06 horas).

A notação de Viéte e as transformações de Tschirnhaus, o teorema fundamental da Álgebra (Euler e Gauss), raízes da unidade, os trabalhos de Vandermonde e Lagrange, as contribuições de Ruffini, Cauchy e Abel, Galois e a resolução de equações por radicais.

09 - Uma breve história do Cálculo (07 horas).

A geometria analítica de Fermat e Descartes, o método das tangentes, a quadratura da parábola, o cálculo de Newton, o cálculo de Leibniz e a evolução do cálculo infinitesimal.

10 - Filosofia da Matemática (Século XX) (06 horas).

O Logicismo de Russell e Whitehead, o Formalismo de Hilbert e o Intuicionismo de Brouwer.

Além disso, tratamos de outras formas de abordagem, como o estudo de tópicos selecionados: História da Trigonometria, História do Cálculo, História da álgebra, com o uso ou não de textos específicos como AABOE (2002); do estudo de textos clássicos como: o "Traité des Substitutions et des Équations Algébriques" de JORDAN (1957), o "Reflexions sur la Résolution Algébrique des Équations" de LAGRANGE(1771), o "Disquisitiones Arithmeticae" de GAUSS (1801), o "Volständige Anleitung zur Algebra" de EULER (1770), o "Líber Abaci" de FIBONACCI (1202), o "Ars Magna" de CARDANO (1545) ou o "Al - Jabr" de AL Khowarizmi (século IX); e do que 
denominamos de estudo da evolução (ou desenvolvimento de conceitos). Buscando uma apresentação menos generalizante a partir de uma escolha de conceitos fundamentais, como descrito a seguir,

Figura 02: Elencando conceitos fundamentais de subáreas da Matemática

\section{EVOLUÇÃO DE CONCEITOS}

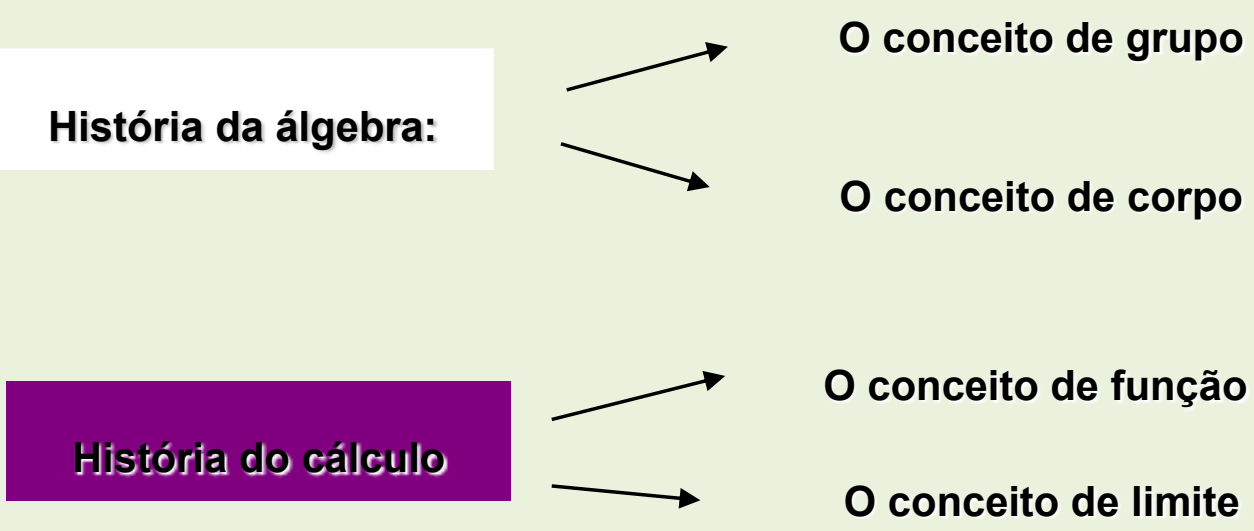

História da Geometria

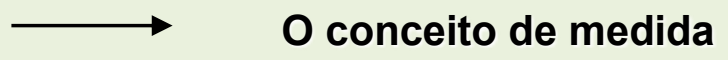

História da trigonometria

Fonte: Produzido pelo autor.

Consideramos que, o uso do componente histórico no ensino de matemática se baseia no conhecimento do processo de desenvolvimento de um conceito e/ou na comparação de estratégias de resolução de um problema. Assim, em um artigo publicado por nós em 2007, Usando História da Matemática para Ensinar Equações Algébricas - EPENN, a resolução de equações algébricas é o tópico matemático utilizado para promover esta integração. 
Podemos considerar três tipos de abordagem em especial, como apresentamos, na figura 03, a seguir, onde destacamos os enfoques: cronológico, tópicos selecionados e evolução de conceitos.

Figura 03: Abordagens (ou enfoques) para o uso da história da matemática como componente metodológica

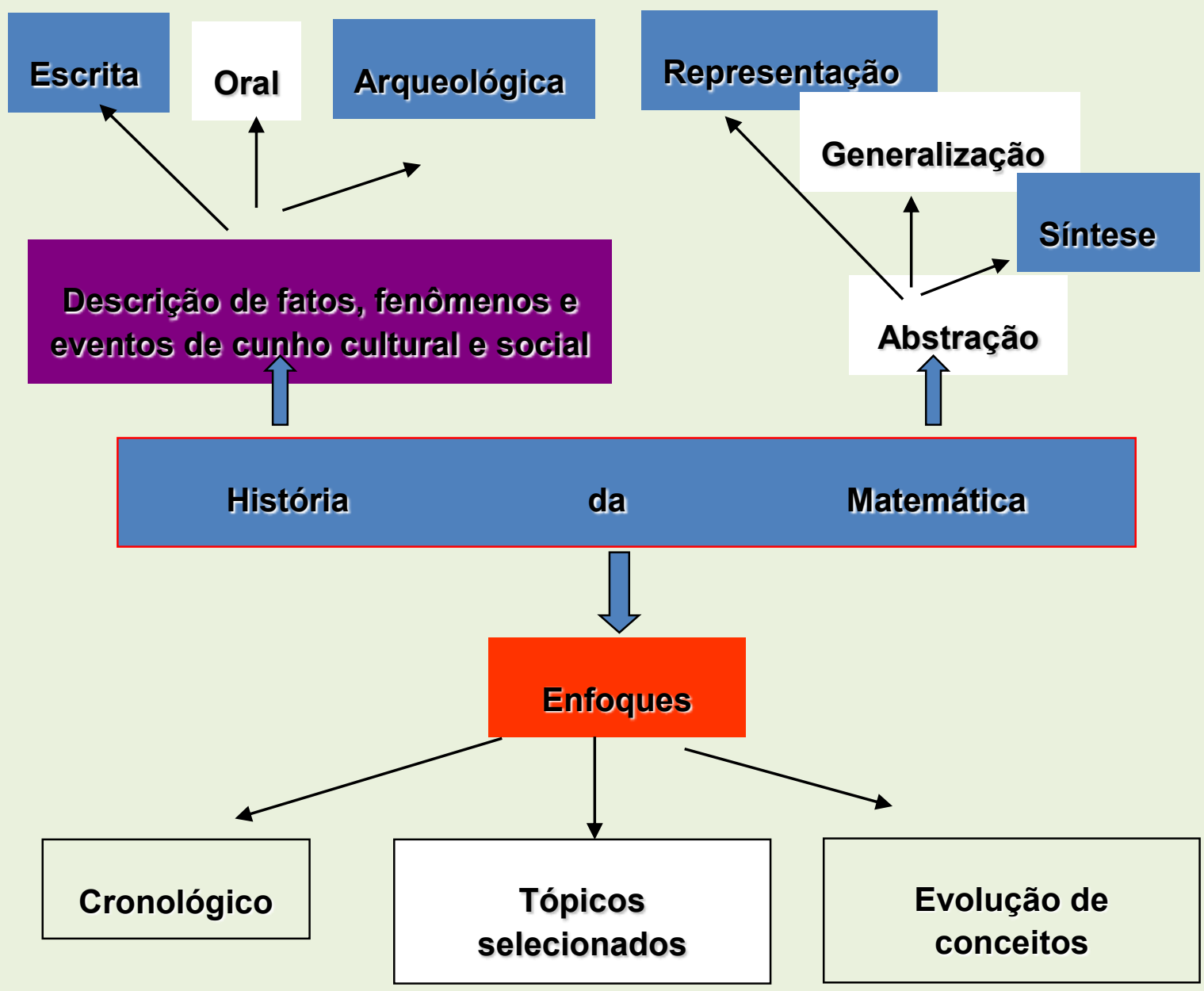

Fonte: Produzido pelo autor.

Uma classificação que apresenta diferenças com a dada por Barros (2004) que trata o campo da história a partir de suas dimensões, abordagens e domínios. E que se faz diretamente conectada as ações do ver a História, fazer a história e escolher os temas a serem trabalhados.

Para Barros (2004), Dimensões, Domínios e Abordagens são critérios que não se misturam, mas se complementam. As Dimensões costumam sofrer alterações em uma forma mais lenta, às vezes levam décadas; são de 
Longa duração. As Abordagens costumam surgir, alterar-se ou serem desativadas com uma rapidez maior, cumprem uma espécie de média duração enquanto que os Domínios surgem e desaparecem com a rapidez da curta duração, às vezes caracterizando modismos.

Figura 04: Apresentação do Campo Histórico

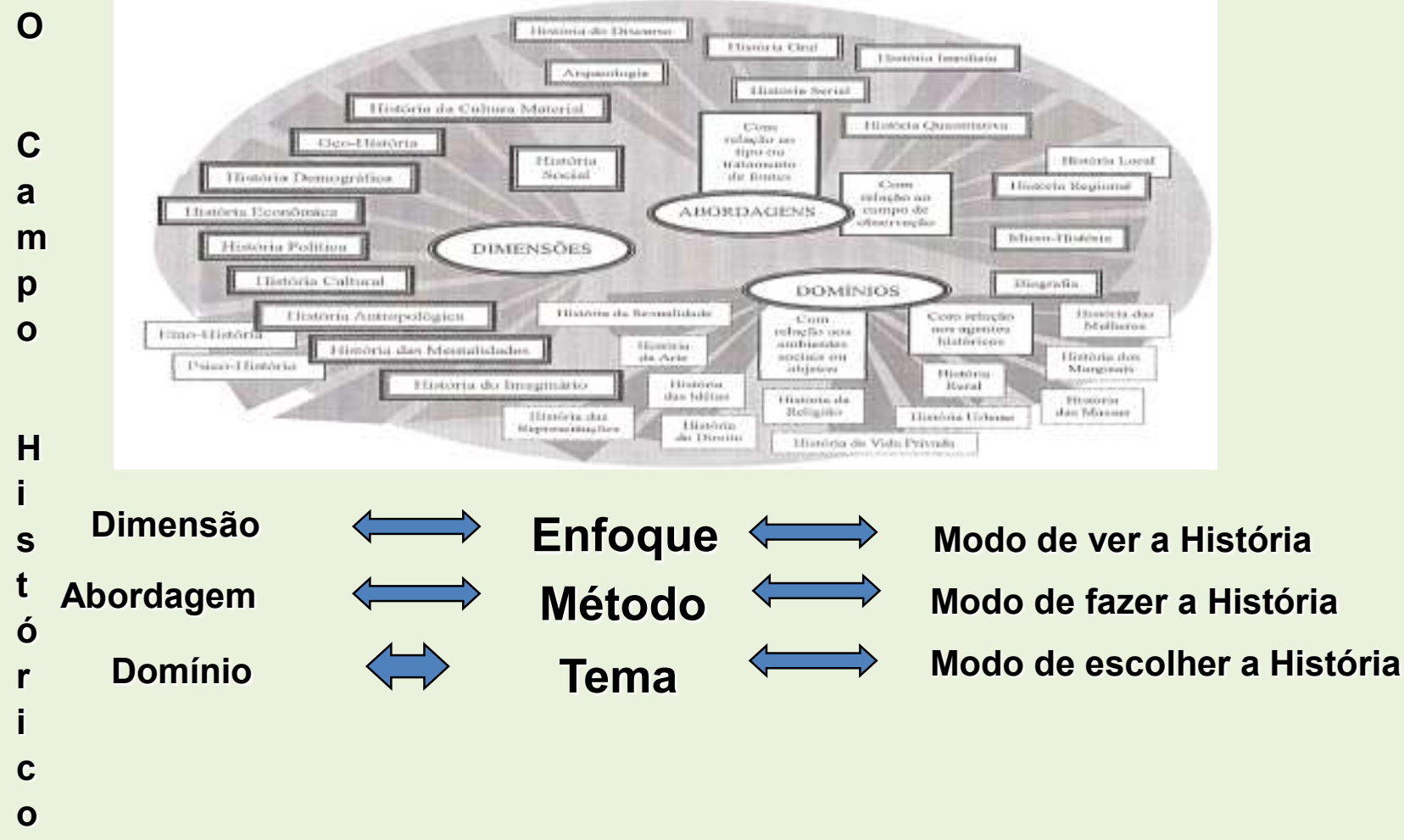

Fonte: Elaborado pelo autor a partir do proposto por Barros (2004, p. 19).

Por princípio, os critérios de classificação que estabelecem domínios na história referem-se primordialmente às temáticas (Campos Temáticos) escolhidas pelos historiadores.

Muitos domínios, a princípio, intersectam diferentes dimensões históricas, e certamente com várias abordagens; entretanto, existem domínios que tem muito mais afinidade com uma determinada dimensão, dada sua natureza temática. Como, por exemplo, a história da arte e a história da literatura como temas da história cultural (BARROS, 2004).

Conforme estamos vendo, e em acordo com Barros (2004, p. 182), os domínios tendem a serem englobados por uma dimensão ou então 
partilhados preferencialmente por duas ou mais dimensões. Mas é possível ainda que algum campo que hoje esteja sendo tratado como domínio, mas que possua uma abrangência em potencial possa vir a transformar-se em uma dimensão. Com relação à história da matemática, foi o que aconteceu com a teoria dos grupos no caso da Álgebra e deve acontecer com teoria da integração no caso do Cálculo, ver figura 05.

Figura 05: (a) llustração do Domínio - Dimensão: História da Álgebra

(b) llustração do Domínio - Dimensão: História do Cálculo

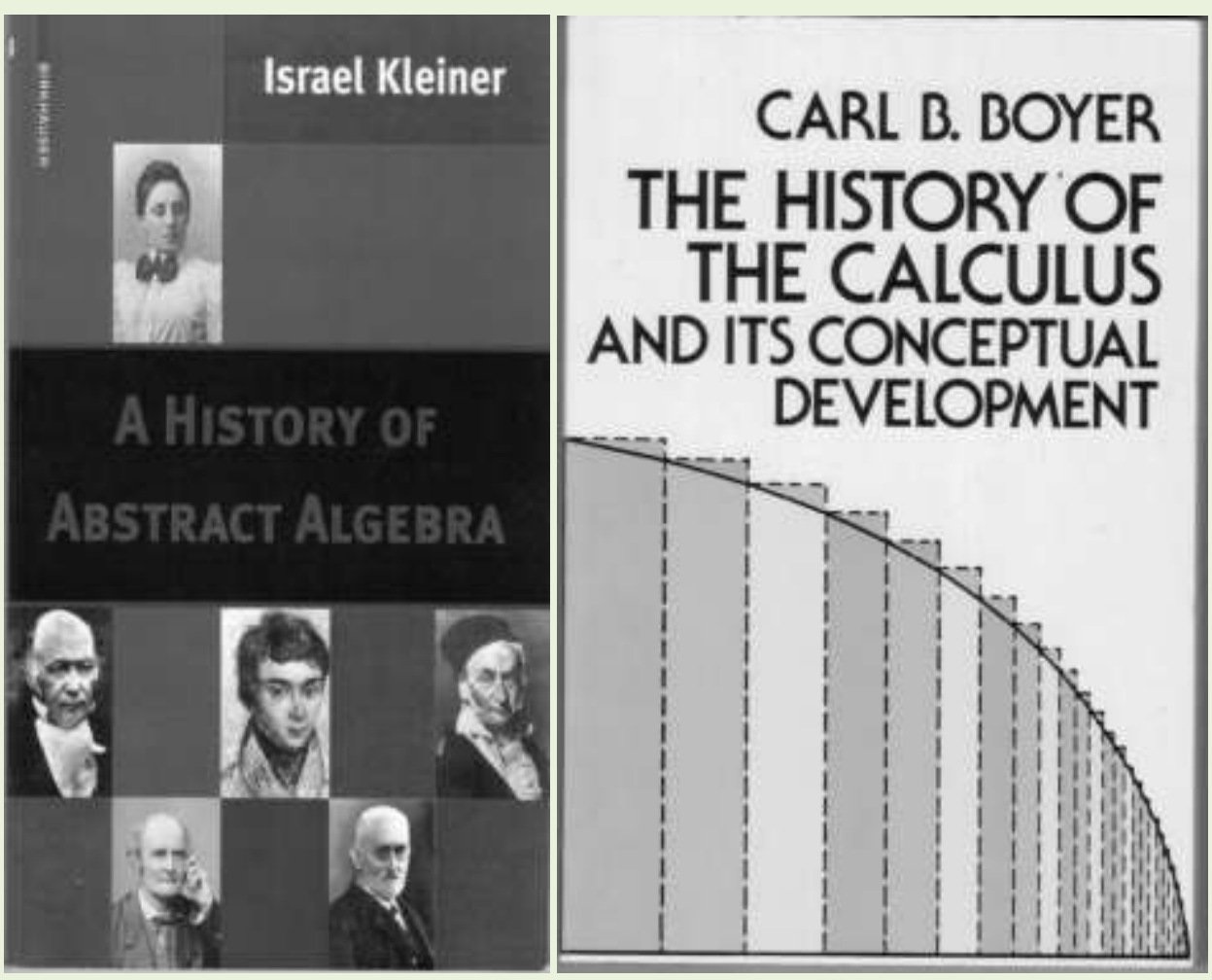

Fonte: Acervo do autor.

Na abordagem que considera a evolução de conceitos, Brandemberg (2010) trata do conceito de Grupo, Brandemberg (2015) do conceito de Integral e Mafra (2009) trata do conceito de Função. Os conceitos são apresentados em uma determinada sequência, não necessariamente linear, buscando a obtenção de seu significado, geralmente, a partir da apresentação de conceitos elementares, obtidos em estágios anteriores, fundamentais para o seu desenvolvimento. 
Assim, no caso do conceito de função, em acordo com Mafra (2009) podemos partir da pergunta "O que entendemos por função, ou o que pensamos sobre o conceito de Função?".

Noções do que viria a ser chamado de funções já aparecem nos trabalhos de Descartes (1596-1650) e Fermat (1601-1665). O termo função foi usado inicialmente por Leibniz (1646 - 1716) no ano de 1673, com significado bem diferente do atual.

O conceito adotado no Brasil é o dado por Leonhard Euler (1707 1783), como aparece no introductio in analysin Infinitorum publicado em 1748, "Qualquer expressão analítica formada daquela quantidade e de números e quantidades constantes", e menos formalmente, o que nos livros de educação básica é essencialmente o seguinte: "Diz-se que uma variável y é função de uma variável $x$, se para cada valor de $x$ corresponde um único valor de y". Outro formato é definir função como um subconjunto particular do produto cartesiano de dois conjuntos. Esta definição segue os moldes da escola francesa e os princípios da matemática moderna apresentada pelo grupo Bourbaki em 1939.

Aqui, o conhecimento deste conteúdo histórico nos permite a comparação de estratégias de resolução de problemas e garante ao aluno a percepção do desenvolvimento conceitual e dos aspectos epistemológicos do conceito abordado, bem como as facilidades disponibilizadas pelos métodos estruturados de resolução modernos. Assim, considerando a beleza dos métodos de resolução histórica e relacionandoos a economia de tempo e esforço propiciada pela resolução moderna para resolver tais problemas, além de tentar garantir a aprendizagem existe uma preocupação nossa com o ato cotidiano de ensinar-aprender, considerando as experiências anteriores dos estudantes.

Um problema clássico que garante a comparação de estratégias no processo de resolução é o "problema das duas torres" encontrado no Líber Abaci (1202) escrito por Leonardo Pisano (1175-1250). Cujo enunciado apresentamos a seguir: "In quodam plano sunt due turres, quarum uma est 
alta passibus30, altera 40, et distant in solo passibus 50; infra quas est fons, ad cuius centrum volitant due aves pari volatu, descendents pariter ex altitudine ipsarum; queritur distantia centri ab utraque turri".

Uma tradução livre nos dá o seguinte enunciado, em língua materna: consideramos uma fonte entre duas torres, e que os dois pássaros, partindo do alto das torres com a mesma velocidade chegam à fonte juntos. Queremos então a distância entre a fonte e as torres, que pode ser também obtido a partir da seguinte ilustração apresentada na figura 06.

Figura 06: Ilustração para o problema das duas torres

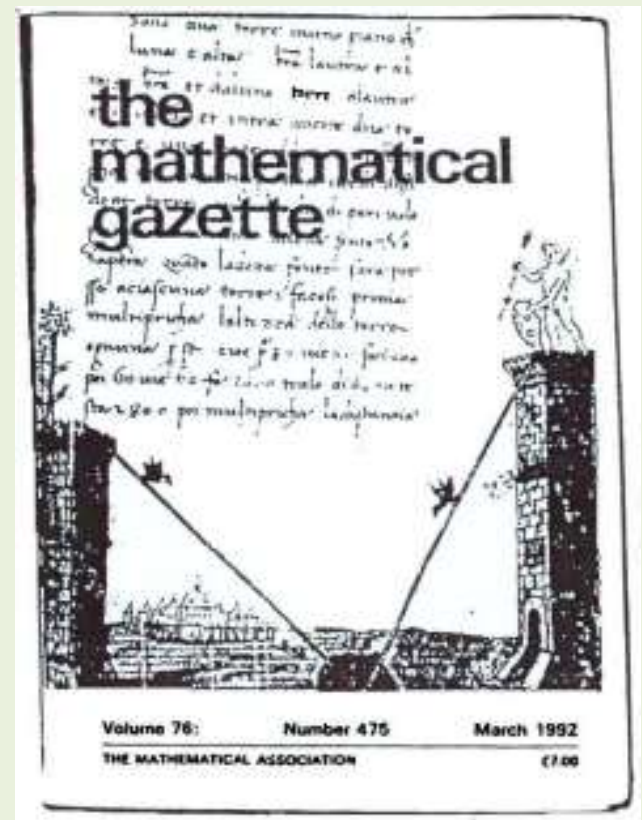

Fonte: Fauvel e Van Maanem (2000).

Nos dias atuais, com o simbolismo algébrico disponível, nossos estudantes com idade variando entre 13 e 14 anos, encontram a solução usando o famoso teorema de Pitágoras (585-500 a.C.) e resolvendo uma equação, a saber, $30^{2}+(50-y)^{2}=40^{2}+y^{2}$ enquanto que em sua resolução é utilizado o método da falsa posição.

Com a utilização deste problema podemos analisar e discutir a estratégia de resolução de Fibonacci, o qual não utiliza o processo algébrico atual e sim operações aritméticas e o chamado método da falsa posição (usado desde o Egito antigo). Este exemplo histórico possibilita aos 
estudantes a oportunidade de comparar os procedimentos aritméticos e algébricos de resolução de problemas.

A comparação de estratégias de resolução de problemas históricos permite ao aluno a percepção do desenvolvimento conceitual e dos aspectos epistemológicos do conteúdo abordado, bem como as facilidades disponibilizadas pelos métodos estruturados de resolução modernos (BRANDEMBERG; MENDES, 2005, p. 04).

\section{COMO COLOCAR ESSA HISTÓRIA DA MATEMÁTICA NO CONTEXTO DE SALA DE AULA?}

Em acordo com Brandemberg e Mendes (2005), consideramos que a história da Matemática deve ser utilizada na elaboração e execução de atividades voltadas a (re) construção de tópicos matemáticos numa perspectiva de compreensão epistemológica dos modos particulares com os quais se articula o saber de uma época, considerando a ruptura que ocorre quando se passa de uma epistémê para outra (FOUCAULT, 2002). É na busca de superação dessa ruptura conceitual que tomamos a história da Matemática como aliada em nossa reconstrução dos conceitos.

Para Mendes (2015), os aspectos epistemológicos favorecem as explicações dos porquês matemáticos e enriquecem o processo de aprendizagem dos alunos. Assim, cabe ao professor, a partir das informações históricas com problemas extraídos de fontes primárias ou remodelados em determinadas épocas buscar novas formas de apresentar um conceito, demonstra um teorema ou mesmo, justificar propriedades fundamentais de algumas estruturas matemáticas.

Em acordo com Mendes (2015), é este posicionamento do professor que permite, a partir do diálogo, a incorporação de novos elementos desenvolvidos ao longo da história para efetivar a compreensão de determinados conceitos trabalhados em sala de aula.

Uma forma de realização desta prática é a elaboração de atividades de cunho histórico como as nomeadas a seguir:

01 - Aspectos do conceito de função: representação analítica, tabelas, diagramas e gráficos. 
02 - A obtenção da área sobre a curva $f(x)=x^{2}$ quando $0 \leq x \leq 1$, considerando o método de aproximação utilizado pelos gregos para quadraturas.

03 - atividades práticas com o Teorema de Pitágoras.

04 - Estudando problemas do papiro de Rhind.

05 - o método de exaustão de Eudoxo-Arquimedes e a quadratura do círculo.

Em acordo com Mendes (2015), os estudantes podem, e devem exercitar a elaboração e a prática de atividades de cunho histórico estruturadas, a saber, atividades que sejam elaboradas com um tema e objetivos bem definidos ligados a obtenção do conhecimento matemático direcionado a um determinado conceito (ou mais de um).

Devemos enfatizar que as atividades perpassam ao simples encaminhamento passo a passo e mecanizado. Devem sim, ser conectadas aos aspectos cotidianos, escolares e acadêmicos da cultura matemática. Uma das implicações deste processo é a discussão a partir dos erros e acertos produzidos na busca de respostas que podem encaminhar a novos desafios na resolução de problemas que ampliem e multipliquem os caminhos ou estratégias criativas de resolução que levem a novas fronteiras do conhecimento matemático.

\section{CONSIDERAÇÕES}

Os professores de Matemática têm enfrentado inúmeras dificuldades no exercício de sua prática docente, sendo o caráter altamente simbólico e não significativo dos conteúdos abordados atualmente a maior delas.

Assim, uma abordagem metodológica como a que propomos, utilizando a História da Matemática como componente metodológico, tem como finalidade principal dar um significado contextual aos conteúdos abordados nos cursos de Matemática e, além disso, servir como elemento de motivação para o desenvolvimento conceitual do aluno. 
Em nossa busca por novas alternativas de transposição didática para o ensino de matemática tomamos a história da Matemática como uma aliada. Esta aliança consiste em trabalhar o desenvolvimento histórico de determinados conteúdos (conceitos, objetos), com vistas a localizar possibilidades pedagógicas que superem as dificuldades encontradas por professores e estudantes de Matemática.

Acreditamos que um estudo das trajetórias percorridas pelos conteúdos matemáticos ao longo dos tempos, com suas idas e vindas, nos permitem uma melhor visualização do desenvolvimento desses conteúdos, que nos permite, e aos nossos alunos, estabelecer relações significativas entre o saber cultural (cotidiano), o saber escolar e as influências do saber acadêmico (científico).

Como professores de matemática, a história do desenvolvimento de conteúdos baliza nossas ações que conduzem a um exercício de reconstrução histórico-epistemológica dos conceitos que pretendemos ensinar em nossa prática de sala de aula; permitindo ao nosso aluno o desenvolvimento efetivo de habilidades para a pesquisa, leitura, escrita e análise de trabalhos em sua formação acadêmica e ampliando sua capacidade de aprendizagem (MENDES, 2015).

\section{REFERÊNCIAS}

AABOE, A. Episódios da História Antiga da Matemática - segunda edição. Tradução: João Bosco Pitombeira de Carvalho. Rio de Janeiro, RJ: SBM, 2002.

BOYER, C.B. História da Matemática. Tradução: Elza F. Gomide. São Paulo, SP: Edgard Blucher, 1993.

BOYER, C.B. The History of the Calculus and its Conceptual Development. New York: Dover, 1959.

BRANDEMBERG, J. C. O Uso de problemas históricos no ensino dos fundamentos de Álgebra - Seminários do CCSA - Natal, 2006.

BRANDEMBERG, J. C. Usando a História da Matemática para ensinar equações algébricas - EPENN - Maceió, 2007.

BRANDEMBERG, J. C. Uma análise histórico epistemológica do conceito de Grupo. São Paulo, SP: Livraria da Física, 2010. 
BRANDEMBERG, J. C. Das quadraturas gregas as somas de Riemann Darboux. Belém, PA: SBEM, 2015.

BRANDEMBERG J. C. MENDES, I. A. Problemas históricos e ensino de Matemática - III EPAEM - Belém, 2005.

BARROS, J. A. O Campo da História: Especialidades e Abordagens Petrópolis, RJ: Vozes, 2004.

CHAQUIAM, M. Trilhos da Matemática um resultado da disciplina história da matemática. SBEM, 2006.

FAUVEL, J.; VAN MAANEM, J. History in mathematics education. EUA: Kluwer academic publishers, 2000.

FOSSA, J. A. Ensaios sobre a educação Matemática. Belém, PA: Eduepa, 2001.

FOUCAULT, M. As Palavras e as Coisas. 8. ed. São Paulo: Martins Fontes, 2002.

KLEINER, Israel. A History of Abstract Algebra. Boston: Birkhauser, 2007.

MAFRA, J. R. Um desenvolvimento histórico sobre o conceito de função. 1. ed. Belém, PA: SBHMat, 2009.

MENDES, I. A. O uso da história no ensino da Matemática reflexões teóricas e experiências. Belém, PA: Eduepa, 2001.

MENDES, I. A. História da Matemática no ensino: entre trajetórias profissionais, epistemologias e pesquisas. São Paulo, SP: Livraria da Física, 2015.

OLIVEIRA, M. C. A., FRAGOSO W. C. História da Matemática: história de uma disciplina. Revista Diálogo Educacional, v. 11, n. 34, p. 625-643, Curitiba, PR: 2011.

VENTURIN, J. A. Uma Proposta para a Disciplina História da Matemática. SBHMAT, 2011.

Recebida em: Fevereiro de 2017

Aceita em: Abril de 2017 